\title{
Modeling of Polluted High Voltage Insulators
}

\author{
Omkar Singh $^{1}$, Rishabh Kushwaha ${ }^{2}$ \\ ${ }^{1-2}$ Department of Electrical Engineering Indian Institute of Technology (BHU), Varanasi, India
}

\begin{abstract}
High voltage insulators play a very important role in the transmission of power from generation to the consumer end, and in protecting the supporting towers from the high voltage lines as well as it also prevents the flashover due to the sudden rise of voltage and due to other causal factors. In this paper we have analyzed the effects of pollution on the insulator on the critical flashover voltage. Particularly, we have achieved our result by energy analysis of the insulator and the line supplying the energy. Some modification as per the requirement is done from the account of the value of constants such as ' $A$ ' the arc constant ' $n$ ' the arc index and ' $K$ ' a constant multiplied before ' $R_{p}$ ' the resistance of the polluted layer. Overall a new equation of flashover voltage is achieved which differs from the model [1] by some factor i.e., constant.
\end{abstract}

Keywords: Flashover voltage, Arc constant, Arc index, ESDD (equivalent salt deposition density)

\section{Introduction}

Modeling of polluted insulators for the determination of flashover voltages prior the insulator failure is used in the transmission line application. The modeling is not done using any type of experiments on the insulators. It is the theoretical analysis of the various research papers published on the very same subject. In the development of this paper we have incorporated some of the ideas and explanation of the previous theories and equations with modification to reach the higher accuracy. The study of different type of insulators is done w.r.t their geometrical structures, as it is going to play a key role in the determination of the flashover voltages. In the modern days transmission system the flashover of the insulators is common, so this requires a great concern over the subject. In this paper the various equations of $\mathrm{V}$ the flashover voltage is compared with the approximate mathematical equation of the same, which is obtained using numerical method of approximation. And certain new variables are added to the final expression for the flashover voltage V. the model of Ghosh \& Chatterji[1], Topalis[2], Gorur[3], Dhabhi M[4] have been compared with the approximate mathematical model and some important conclusions have been obtained.

\section{Details of proposed model}

The development of models for the flashover of polluted insulators which could take into account the real experimental conditions is not an easy task because of the complexity of the phenomena which can occur (Rizk 1981). Indeed, the non-uniformity of the polluted distribution due to the non-uniformity of deposits, wetting and drying leads to the appearance of multiple dry bands and then to multiple arcs. Nevertheless, many attempts have been made to generate models allowing one to predict roughly the critical characteristics of the polluted insulators (the flashover voltage, critical length and leakage current). For that purpose, the assumptions that there is a single dominant arc, a uniform pollution distribution and uniform wetting have been made. So, the arc is assumed to move only on the surface of the insulator.

In the following model, we will consider similar assumptions.

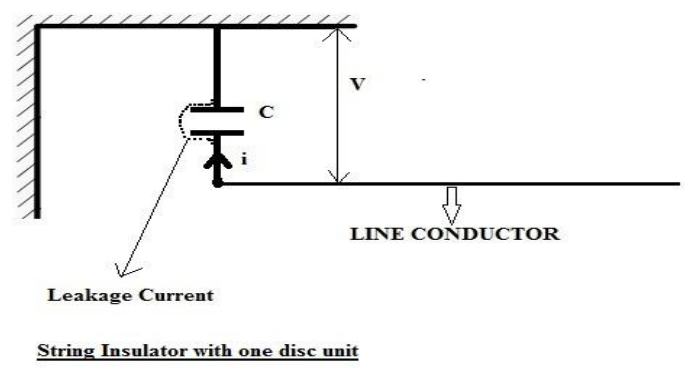

fig.1

By energy analysis of the circuit diagram i.e., power supplied before leakage current came into effect is equal to the power at the present condition. 
$: V * I=\frac{C * V^{2}}{2}+I^{2} *(R p *(L-x))+I^{2} * R a * x(1)$

where $\mathrm{x}$ is the length of the arc, $L$ is the leakage distance of the insulator and $\mathrm{I}$ is the leakage current. The resistance Ra per unit length of the $\operatorname{arc}(\Omega / \mathrm{cm})$ is defined as follows

$: R a=A * I^{(-n+1)}$

Where A and $\mathrm{n}$ are the arc constant and Rp, per unit length of the pollution layer $(\Omega / \mathrm{cm})$ is

$: R p=\frac{1}{\pi D e q \sigma}$

where Deq is the equivalent diameter of the polluted insulator and $\sigma$ is the surface conductivity, which is dependent on the equivalent salt deposit density C (ESDD), by

: $\sigma=(369.05 . C+0.42)$

where $\mathrm{C}$ is expressed in $\mathrm{mg} / \mathrm{cm}^{2}$.The equivalent diameter Deq of the insulator is given by

$: D e q=\frac{\mathrm{L}}{\pi \mathrm{F}}$

Where $\mathrm{F}$ is the form factor of the insulator which is given by $: \mathrm{F}=\frac{1}{\pi} \int \frac{d l}{D(l)}$

By solving (1) we get a quadratic equation in variable $\mathrm{V}$, which can be solved easily to get the critical voltage.

By solving we get the following result,

$: \frac{\mathrm{CV}^{2}}{2}-\mathrm{VI}+\mathrm{I}^{2}\left(R_{p}(\mathrm{~L}-\mathrm{x})\right)+\mathrm{I}^{2} R_{a} \mathrm{x}=0$ (2)

Before finding the roots of the equation, we are more concerned about the discriminant of the quadratic equation which is given by,

$: \mathrm{D}=I^{2}-2 \mathrm{C} I^{2}\left(\left(R_{p}(\mathrm{~L}-\mathrm{x})\right)+R_{a} \mathrm{x}\right)$

$: \mathrm{D}=I^{2}\left[1-2 \mathrm{C}\left(\left(R_{p}(\mathrm{~L}-\mathrm{x})\right)+R_{a} \mathrm{x}\right)\right]$

$: \sqrt{\mathrm{D}}=\mathrm{I}\left[1-2 \mathrm{C}\left(\left(R_{p}(\mathrm{~L}-\mathrm{x})\right)+R_{a} \mathrm{x}\right)\right]^{1 / 2}$

By considering first three term of the binomial expansion and putting the corresponding value of discriminant in the solution of quadratic equation, $x=\frac{-b \pm \sqrt{b^{2}-4 a c}}{2 a}$, we get that
$: \mathrm{V}=\mathrm{IK}(1+\mathrm{KC} / 2)(2)$
Where $\mathrm{K}=\mathrm{R}_{\mathrm{p}}(\mathrm{L}-\mathrm{x})+\mathrm{R}_{\mathrm{a}} \mathrm{x}$

When differentiating the above equation with respect to $\mathrm{x}$ and equating to zero, we obtain the critical current $\mathrm{I}$ : $: \mathrm{I}=(\mathrm{A} /(\mathrm{Rp}))^{(1 / \mathrm{n}+1)}(3)$

On the other hand, by differentiating equation with respect to I and setting it equal to zero, we obtain $: \operatorname{Rp}(\mathrm{L}-\mathrm{x})+(1-\mathrm{n}) \mathrm{A} I^{-n}+\frac{\mathrm{C}\left[K^{2}-2 \mathrm{nKAI} I^{-n} \mathrm{x}\right]}{2}=0(4)$

and by combining equations (3) and (4), we obtain the critical arc length $\mathrm{x}_{\mathrm{c}}$ as

$: \mathrm{x}_{\mathrm{c}}=\frac{L}{n+1}\left[1-\frac{R p C}{2(1+R p C)}\right]$

The plot of suggested model VS various other model are shown as below

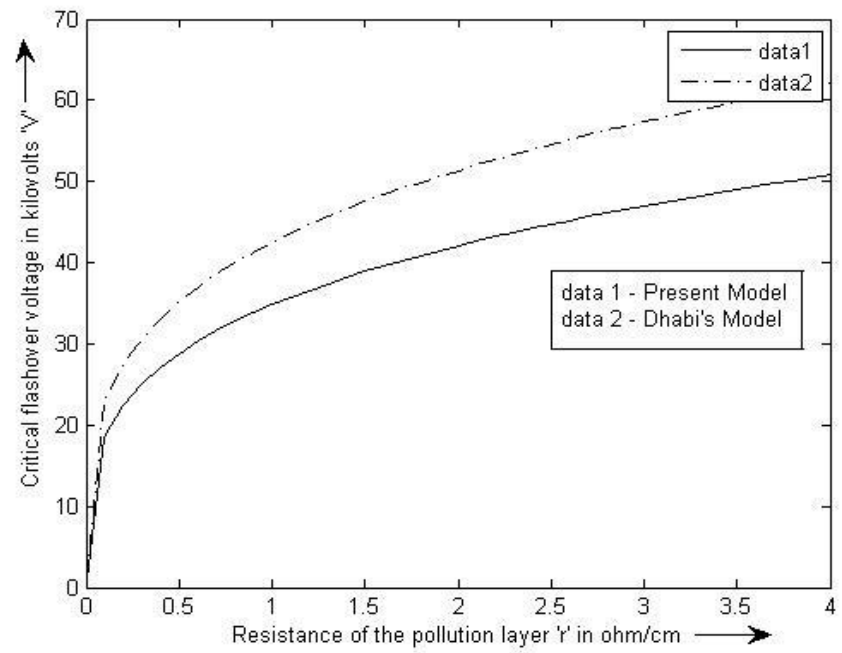

fig. 2 


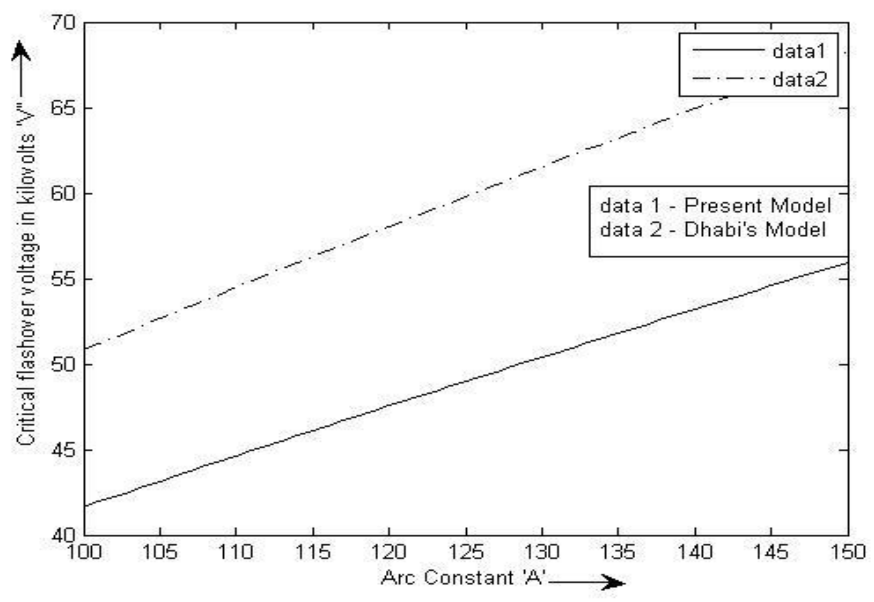

fig. 3

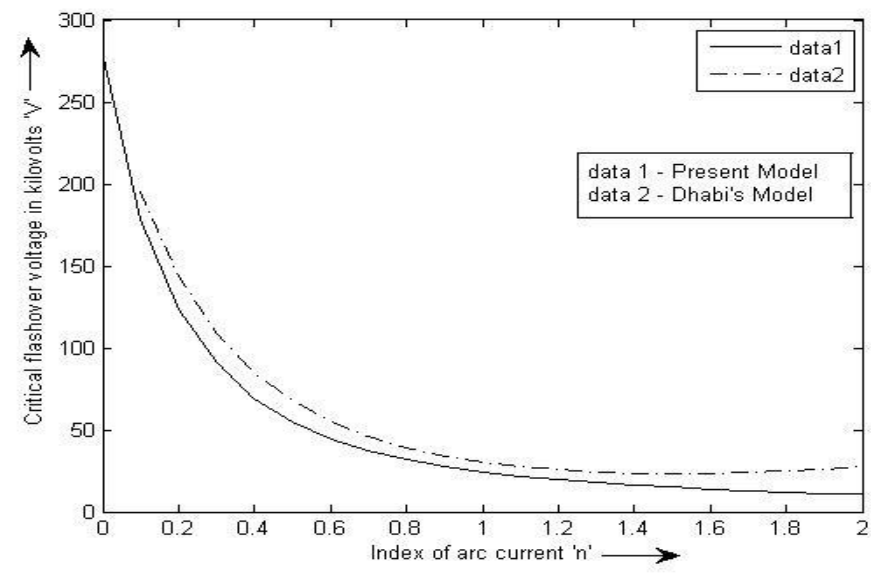

fig.4

As for as the fig. 3 and 4 are concerned, they show the different aspects of studies that can be done on the particular equation which we have got. Our model as shown in the diagram lies always above the plot of Dhabi's model for the same parameters.

From fig. 3 the important thing which can be noted down is that there is a considerable gap between the two plots, as our plot is considerably lower than the other model with which it is compared. Which gives us a great advantage in modelling of the insulator for the case of high voltage application. As low value of flashover voltage is achieved for same value of arc constant this implies that where other model was giving higher value of flashover voltage, our model suffice with the experimental one and it is quite accurate with some level of tolerance

From fig.4, it is observed that there is an appreciable amount of similarity still our plot is below the plot of the other model. Which signifies that the two models have the same sort of reasoning

and logic but addition or removal of some parameter in the final flashover equation gives birth to a brand new equation. The advantage of the model deduced from the particular study is that, if the insulator is modelled according to our model the flashover voltage will be reduced to a greater margin.

The flashover of the polluted insulator occurring at voltages lower than that suggested by earlier paper given in the references shows that there is flashover at those voltages[1],[2],[3] but it occurs below those voltages i.e., at the voltage approximately near to that suggested by this model.

The above discussion was based on the plots as shown in the fig.2, fig.3and fig.4.

\section{Absolute study}

The following equation of flashover voltage as obtained-

$: V=\sqrt[n+1]{\frac{A}{R_{p}}}\left[\frac{L}{n+1}\left\{1-\frac{R_{p} C}{2\left(1+R_{p} C\right)}\right\}\left(R_{a}-R_{p}\right)+R_{p} L\right]$

And the three different plots explain this. 
From the equation perspective the additional term containing ' $\mathrm{C}$ ' is major distinguishing factor as well as it brings accuracy as it reduces the tolerance level by certain percentage. The equation is almost similar to the previous equations as obtained by earlier researchers.

By neglecting $\mathrm{KC} / 2$ term in equation-(2), as $\mathrm{KC} / \mathrm{r}<<<1$, we get our flashover equation as given below:

$: V=\sqrt[n+1]{\frac{A}{R_{p}}}\left[R_{p} L\right](7)$

Which shows that it is a function of Rp, which is obviously nonlinear. It depends on the value of $\mathrm{n}$.

As the value of $n$ increases, the variation of flashover with $R_{p}$ tends to linearize itself. As $n$ tends to infinity, flashover is proportional to $\mathrm{R}_{\mathrm{p}}$.

Most of the work on pollution flashover of insulators have used constant values of $\boldsymbol{A}$ and $\mathrm{n}$ for different atmosphere, assuming the arc to glide through either steam $(A=530, n=0.24)$ or water vapor $(A=63, \mathrm{n}=$ 0.76). Alston [5] recommended that a combination $A=530$ and $\mathrm{n}=0.24$ can yield good results for most problems. But there is still no consensus as to what values of $A$ and $n$ should be used in case of different polluted atmosphere.

In fact, the optimal combination of $A$ and $n$ may be dependent on the chemical nature of the pollutants. In this model we have have used different values of $\mathrm{A}$ and $\mathrm{n}$ representing different electrolyte. Different sets of $\mathrm{A}$ and $\mathrm{n}$ in the following table represent $\mathrm{NACl}, \mathrm{CaCl}_{2}$ and $\mathrm{FeCl}_{3}$ respectively.

\section{Comparison of modelled output with experimental result}

\section{TABLE 1}

Showing the Critical Flashover Voltage by the present model and Practical value of it.

\begin{tabular}{|c|c|c|c|c|c|}
\hline $\begin{array}{l}\mathrm{R}_{\mathrm{p}} \\
(\mathrm{K} \Omega / \mathrm{cm})\end{array}$ & $\mathrm{L}(\mathrm{cm})$ & $\mathrm{A}$ & $\mathrm{n}$ & $\begin{array}{l}\mathrm{V} \text { model in } \\
\mathrm{KV}\end{array}$ & $\begin{array}{l}\text { V(exp) } \\
\text { KV }\end{array}$ \\
\hline 10 & 8 & 360 & 0.59 & 9.51 & 11 \\
\hline 15 & 5 & 360 & 0.59 & 7.17 & 8 \\
\hline 10 & 12 & 461 & 0.42 & 12.50 & 14 \\
\hline 15 & 8 & 461 & 0.42 & 9.61 & 11 \\
\hline 10 & 5 & 270 & 0.66 & 6.07 & 7 \\
\hline 21.6 & 8 & 270 & 0.66 & 11.03 & 12 \\
\hline
\end{tabular}

From the Table 1, it can be seen that for values greater than 10, the error is quite high(in between 10-15\%) but for the values less than 10 , error is less than $7 \%$. So we can say that this model can be used for the insulator with high contamination level.

This model is based on an energy balance, an equivalent electrical circuit and the physical characteristics of the arc. The results given by the model that we elaborated are in good accordance with those obtained using the known empirical relations, especially insofar as the critical current and voltage are concerned.

\section{Conclusion}

The deficiency of applying the classical equation for the determination of critical flashover voltage of polluted insulators has been overcome by the selection of appropriate arc constants $\boldsymbol{A}$ and $\boldsymbol{n}$ for different chemical composition of the pollutants. The proposed mathematical model $V=f\left(R_{p}, L, A, n\right)$ thus takes into account the effect of change in the chemical nature of the pollutants under ac voltage application to predict accurately the flashover voltage. The computed results closely follow the experimental values. The model is validated against experimental and theoretical data of other researchers, and is observed to be good in predicting both critical V and I of practical insulators of a variety of geometries.

\section{Acknowledgements}

The present paper wouldn't be completed without the help and specified direction of our respected Professor Ravi S. Gorayan of Department of Electrical Engineering Indian Institute of Technology (BHU), Varanasi. We are thankful and are highly obliged to him. Moreover we are thankful to our mutual support without which the paper wouldn't be completed. Finally the advises of our seniors was also contributing, so we thank to them with the bottom of our heart.

\section{References:}

[1] Polluted Insulator Flashover Model for ac Voltage P. S. Ghosh and N. Chatterjee, IEEE Transactions on Dielectrics and Electrical Insulation Vol. 2 No. 1, February 1995.

[2] Dielectric behaviour of polluted porcelain insulators by F.V.Topalis, I.F.Gonos and I.A.Stathopulos.

[3] Gorur, R. S., \& Olsen, R. (2006). Prediction of flashover voltage of insulators using low voltage surface resistance measurement. Power System Engineering Research Center, Final Project Report, Arizona State University. 
[4] A new proposal model for flashover of polluted insulators by N Dhahbi-Megriche, A Beroual and L Krahenbuhl J. Phys. D: Appl. Phys. 30 (1997) 889-894.

[5] Alston, L. L., \& Zoledziowski, S. (1963). Growth of discharges on polluted insulation.Proceedings of the IEEE, 110(7), $1260-1266$.

[6] Suflis, S. A., Gonos, I. F., Topalis, F. V., \& Stathopulos, I. A. (2003). Study of the dielectric behaviour of non-uniformly polluted insulators. In XIIIth international symposium on HV engineering, Netherlands.

[7] Singer, H: "Present and Future Topics of HV Field Calculation and Measurement, Proceedings of the $9^{\text {th }}$ International Conference on High Voltage Engineering, (Graz University of Technology), September 1995, pp. 9008-(1-4).

[8] A. H. Rahal and C. Huraux, "Flashover Mechanism of HV Insulator", IEEE Trans. PAS, Vol. 98, No. 6, pp. 2223-2231, Nov./dec. 1979.

[9] The Electric Field Of Insulators WL Vosloo and JP Holtzhausen, Eskom / University of Stellenbosch, South Africa

[10] Boheme H and Obenaus F 1966 Pollution flashover tests on insulators in the laboratory and in systems and the model concept of creepage path flashover, Cigr'e, paper 407.

[11] Kimoto, I., Fujimura, T., \& Naito, K. (1973). Performance of insulators for direct current transmission line under polluted condition. IEEE Transactions on PAS, 92,943-949.

[12] Sundararajan R, Sadhureddy N R and Gorur R S 1995 Computer aided design of porcelain insulators under polluted condition IEEE Trans. Dielectrics Electric Insulator. 2 121-7.

[13] Wilkins, R. (1969). Flashover voltage of high voltage insulators with uniform surface pollution films. Proceedings of the IEEE, 116, 457-465.

[14] Dhahbi-Megriche, N., \& Beroual, A. (2000). Flashover dynamic model of polluted insulators under ac voltage. IEEE Transactions on Dielectrics and Electrical Insulation, 7(2), 283-289.

[15] Wilkins R and Albaghdadi AJ 1971 Arc propagation along an electrolyte surface Proc. IEE 118 $1886-92$

[16] Gencoglu, M. T., \& Cebeci, M. (2008). Computation of AC flashover voltages of polluted HV insulators using a dynamic arc model. European Transactions on Electrical Power, doi:10.1002/etep.249.

[17] P. S. Ghosh, S. Chakravorti and N. Chatterjee, "Pollution Flashover of Electrolytic Surface under Power Frequency High Voltages", IE (India), Journal-EL, pp. 180-184, 1992.

[18] Phillips, A.J. et al: "Water Drop Corona on Full-Scale 500 kV Non-Ceramic Insulators ", IEEE Transactions on Power Delivery, Vol. 14, No. 1, January 1999, pp. $258-265$. 